\title{
Modeling of metallocene catalyzed propylene polymerization in fluidized bed reactors
}

\author{
Chew-Sang Law ${ }^{1, *}$ and Mohd Azlan Hussain ${ }^{1}$ \\ ${ }^{1}$ Department of Chemical Engineering, Faculty of Engineering, University of Malaya, 50603 Kuala Lumpur, Malaysia
}

\begin{abstract}
A study was performed to improve the model for metallocene catalyzed polyolefin polymerization in fluidized bed reactor by adapting multi-scale modeling approach. Monomer concentration and reactor temperature was predicted using kinetic model of polypropylene homopolymerization coupled with well mixed reactor models of fluidized bed reactor. Well mixed model typically used for Ziegler-Nata was selected as supported homogeneous metallocene exhibited heterogeneous property similar to ZN catalyst. Result of simulation showed that model was able to predict reaction temperature accurate with around $3 \%$ over-prediction of reactor temperature, which is more accurate than previous model. Model predicted decrease in final monomer concentration from $0.9929 \mathrm{~mol} / \mathrm{s}$ to $0.986 \mathrm{~mol} / \mathrm{s}$ when initial reactor was raised from $25 \mathrm{C}$ to $75 \mathrm{C}$.
\end{abstract}

\section{Introduction}

Polyolefin are considered to the most important commodity polymers today with increasing application in household and the industries. metallocene has been center of many studies since because of the advantages it poses against such as conventional Ziegler Natta and Phillips catalyst. The solution process was the pioneering commercial process to use metallocene catalyst to produce polyethylene. Gas phase and Slurry process will utilize heterogeneous catalyst where metallocene catalysts will need to be supported.

Reactor configuration of polyolefin polymerization includes tubular reactor, fluidized bed, continuous/ semicontinuous CSTR, reaction columns and reactors in series. Polymers properties will be impacted by different mixing conditions. In addition, the formed structure of the polymer affects the flow of the complex fluid. Reactor configuration used in modeling studies conducted for metallocene catalyze polyolefin reactor include fluid bed reactor [1], loop reactors [2-5], fixed bed reactor [6]; stirred tank [7-13], and continuous stirred tank reactor with semi-segregation [14].

Modeling of metallocene catalyst system in this study will enable the establishment of relationship between physical reactor parameter such as pressure, temperature and carrier gas velocity with properties of end polymer product. Optimization of final polymer product properties will then be achieved through control of physical reactor condition.

Modeling polymerization of metallocene in fluidized bed reactor was attempted by Meier et al, 2010 [1]. The monomer concentration in the polymer has been calculated with the Flory-Huggins equation in kinetic where the kinetic parameters have been determined by fitting the reaction rate curves with the model. Meier et al., 2010 has developed a compartment model to describe the general in stationary temperature profiles in the reactor and related molecular weight distribution of the polymer. The studies reach a conclusion that the under prediction of the temperature gradient by the model over the annulus is likely caused by the inaccuracies in the input data for the solids circulation rate.

Modeling of polymerization process can be classified to three scales depending on specific properties of process. Micro-scales include polymerization kinetic, and Meso-scales include physical transport phenomena of reaction such as phase heat and mass transfer. The macroscale modeling of polymerization process focused reactor modeling. This study has adapted multi-scale modeling approach for modeling polymerization polymerization of metallocene in fluidized bed. Mechanisms of addition polymerization were modeling and solve using method of moment method in kinetic modeling. Well mixed model establish by McAuley et al has taken into account both meso and macro - scale of modeling by factor in as inter/intra phase mass and heat transfer and semi-batch nature of fluidized bed reactor. Purpose of this study is to establish an accurate model for polymerization of metallocene in fluidized bed reactor based on well mixed model by utilizing more robust kinetic model to improve accuracy the modeling.

Section 2.0 covered the development of multi-scale model, where as Section 3.0 discussed the result and discussion for the studies. Section 4.0 is the Conclusion of the studies.

*Corresponding author: chewsanglaw@ gmail.com 


\section{Modeling development}

This study focused on developing model for $2 \mathrm{t}$ scale of metallocene catalyzed homopolymerization of polypropylene which are the micro scale (kinetic model) and macro scale (reactor model) reaction. Kinetic modeling in this study was adapted from model developed by Nikhil Prakash, 2013 [15]. For reactor modeling, well mixed model was selected as the reaction behavior of a supported homogenous metallocene catalyst would match the characteristic of a heterogeneous Ziegler-Natta and Phillips catalyst process, in a gas phase fluidized bed reactor.

\subsection{Kinetic model}

Kinetic modeling of approach for metallocene catalyzed homopolymerization of polypropylene in this study was adapted from model developed by Nikhil Prakash, 2013 [15]. Prakash applied method of moment as the discretion method in the modeling of metallocene polymerization. Mechanism of reaction is show in Table 1. The reaction rate constants were taken from literature.

Table 1. Mechanism of Polypropylene Polymerization

\begin{tabular}{|c|c|c|}
\hline Reaction & Stoichiometry & Description \\
\hline 1. & Cat + Cocat $\longrightarrow P(0)$ & Instantaneous catalyst activation \\
\hline 2. & $P(0)+M \stackrel{k_{a}}{\longrightarrow} P(1)$ & Chain initiation \\
\hline 3. & $P(i)+M \stackrel{k_{\iota}}{\longrightarrow} P(i+1)$ & Chain propagation \\
\hline 4. & $P(i) \stackrel{k_{s}}{\longrightarrow} P_{d}(0)+D(i)\{$ chain $\}$ & \multirow[b]{2}{*}{ Spontaneous catalyst deactivation } \\
\hline 5. & $P(0) \stackrel{\iota_{i}}{\longrightarrow} P_{d}(0)$ \{site $\}$ & \\
\hline 6. & $P(i)+M \stackrel{i_{4}}{\longrightarrow} D(i)+P(1)$ & Chain transfer to monomer \\
\hline 7. & $P(i) \stackrel{k_{y N}}{\longrightarrow} D(i)+P_{H}^{*}(0)$ & $\beta$-Hydride elimination \\
\hline 8. & $P_{H}^{\prime}(0)+M \stackrel{k_{y}}{\longrightarrow} P(1)$ & Reinitiation after $\beta$-H elimination \\
\hline 9. & $P(i)+M \stackrel{k_{1}}{\longrightarrow} R(i+1)$ & Secondary $(2,1)$ insertion \\
\hline 10. & $R(i)+M \stackrel{k_{i}}{\longrightarrow} P(i+1)$ & Propagation after $(2,1)$ insertion \\
\hline 11. & $R(i)+M \stackrel{k_{\mu \mu}}{\longrightarrow} D(i)+P(1)$ & Chain transfer after $(2,1)$ insertion \\
\hline 12. & $P(i)+$ Cocat $\stackrel{k_{s s}}{\longrightarrow} D(i)+P_{\text {as }}^{*}(0)$ & Chain transfer to cocatalyst \\
\hline 13. & $P_{M e}^{*}(0)+M \stackrel{k_{u s c}}{\longrightarrow} P(1)$ & $\begin{array}{l}\text { Reinitiation after transfer to } \\
\text { cocatalyst }\end{array}$ \\
\hline
\end{tabular}

\subsection{Reactor model}

In the present study, a well mixed model was adapted to describe the dynamic behavior of the metallocene catalyzed polypropylene gas phase fluidized bed reactor. McAuley et al. [16]. concluded the well-mixed model which consider bubbles are small with unrestricted mass and heat transfer between the emulsion and bubbles phases and that the composition and temperature are uniform in the gas phase throughout the bed.

Assumption used in proposed model includes a) Mass and heat transfer resistance between the solid polymer particles and emulsion are negligible due to low to moderate catalyst activity, b) Voidages of bubble and emulsion phase as well as their fractions in the bed can be determine through dynamic two phase structure of gasfluidized beds, c) isothermal reaction operation, d) continuously catalyst fed into the reactor, and e) Constant mean particle size is assumed throughout the bed.

Based on the above assumptions, dynamic material and energy balance equations can be written for the monomer and hydrogen based on the previously mentioned assumptions [17]. The mole balance is shown in Eq. 1.

$$
\begin{aligned}
\left(V \varepsilon_{m f}\right) \frac{d\left[M_{i}\right]}{d t}= & U_{0} A\left(\left[M_{i}\right]_{i n}-\left[M_{i}\right]\right) \\
& -R_{V} \varepsilon_{m f}\left[M_{i}\right]-(1 \\
& \left.-\varepsilon_{m f}\right) R_{i}
\end{aligned}
$$

where $\mathrm{V}=$ reactor volume $\left(\mathrm{m}^{3}\right), \mathrm{M}_{\mathrm{i}}=$ concentration of component $\mathrm{I}$ in the reactor $\left(\mathrm{kmol} / \mathrm{m}^{3}\right), \mathrm{U}_{0}=$ superficial gas velocity $(\mathrm{m} / \mathrm{s}), A=$ cross sectional area of reactor $\left(\mathrm{m}^{2}\right)$, $\left[\mathrm{M}_{\mathrm{i}}\right]_{\text {in }}=$ concentration of component $\mathrm{I}$ in the inlet gaseous stream $\left(\mathrm{kmol} / \mathrm{m}^{3}\right), \mathrm{R}_{\mathrm{v}}=$ volumetric polymer phase out flow rate from the reactor $\left(\mathrm{m}^{3} / \mathrm{s}\right), \varepsilon_{\mathrm{mf}}=$ void fraction of bed at minimum fluidization, $R_{i}=$ instantaneous rate of reaction of monomer I.

The energy balance is derived in Eq. 2.

$$
\begin{aligned}
{\left[\sum_{i=1}^{m}\left[M_{i}\right] C_{p i} V \varepsilon_{m f}\right.} & +V\left(1-\varepsilon_{m f}\right) \rho_{p o l} C_{p, p o l} \frac{d T}{d t} \\
& =U_{0} A \sum_{i=1}^{m}\left[M_{i}\right] C_{p i}\left(T-T_{r e f}\right) \\
& -U_{0} A \sum_{i=1}^{m}\left[M_{i}\right] C_{p i}\left(T-T_{r e f}\right) \\
& -R_{V}\left[\sum_{i=1}^{m}\left[M_{i}\right] C_{p i} \varepsilon_{m f}\right. \\
& \left.+\left(1-\varepsilon_{m f}\right) \rho_{p o l} C_{p, p o l}\right](T \\
& \left.-T_{r e f}\right)+\left(1-\varepsilon_{m f}\right) \Delta H_{R} R_{P}
\end{aligned}
$$

where $\mathrm{M}_{\mathrm{i}}=$ concentration of component $\mathrm{I}$ in the reactor $\left(\mathrm{kmol} / \mathrm{m}^{3}\right), \mathrm{C}_{\mathrm{pi}}=$ specific heat of capacity of component $(\mathrm{J} / \mathrm{kgK}), \mathrm{V}=$ reactor volume $\left(\mathrm{m}^{3}\right), \varepsilon_{\mathrm{mf}}=$ void fraction of bed at minimum fluidization, $\rho_{\mathrm{pol}}=$ density of polymer, $\mathrm{C}_{\mathrm{p}}$, $\mathrm{pol}=$ specific heat capacity of solid product $(\mathrm{J} / \mathrm{kgK}), \mathrm{T}_{\mathrm{in}}=$ temperature of inlet gaseous stream $(\mathrm{K}), \mathrm{T}_{\text {ref }}=$ temperature at reference condition $(\mathrm{K}), \mathrm{U}_{0}=$ superficial gas velocity $(\mathrm{m} / \mathrm{s}), \mathrm{A}=$ cross sectional area of reactor $\left.\left(\mathrm{m}^{2}\right),\right), \mathrm{R}_{\mathrm{v}}=$ volumetric polymer phase out flow rate from the reactor $\left(\mathrm{m}^{3} / \mathrm{s}\right), \varepsilon_{\mathrm{mf}}=$ void fraction of bed at minimum fluidization, $\mathrm{R}_{\mathrm{p}}=$ production rate $(\mathrm{kg} / \mathrm{s}), \mathrm{H}_{\mathrm{R}}=$ reactor height $(\mathrm{m})$.

The set of model equations from kinetic model and reactor model which are comprised of stiff, nonlinear and coupled ordinary differential equations are solved numerically using MATLAB 7.0.1 software and the implicit numerical differentiation formulas of ode15s. 


\section{Results and discussion}

A comparative simulation on temperature profile of reaction was conducted to test predictive capability of proposed model. Simulated Temperature profile by model was compared with 1) modeling result from literature and 2) experiment result source from literature, this served to verify the accuracy of the model developed, seen in Figure 1. Modeling result from literature refers to studies conducted by Meier et al, which Meier developed was based on Flory-Higgins equation. The studies conclude that simple well mixed model was not able to describe vertical temperature gradients because no segregation and no mixing phenomena have been taken into account.

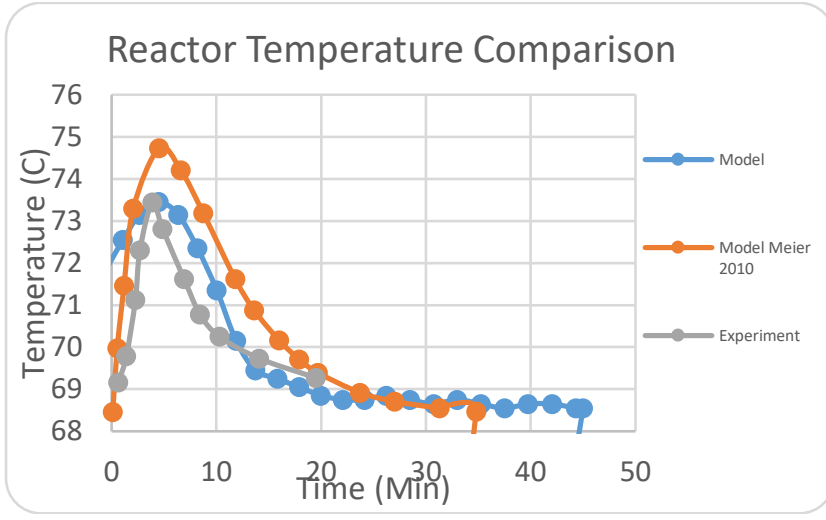

Fig. 1. Reactor Temperature Profile Metallocene catalyzed polymerization in FBR.

It is shown that reactor temperature is proportional to time, until a peak temperature within 10 min of reaction before decline back to starting reactor temperature. Modeling result showed that reactor temperature rises to $76.2{ }^{\circ} \mathrm{C}$ in $5.7 \mathrm{~min}$, reactor temperature from literature model rise to $74.7{ }^{\circ} \mathrm{C}$ within 4.54 min whereas maximum temperature of $73.44{ }^{0} \mathrm{C}$ was attained within $3.9 \mathrm{~min}$ by experiment studies.

The development multi-scale model was able to predict reactor profile more accurately as compared to Model developed by Meier et al, 2010, this is mainly contributed by the incorporation of a robust kinetic model into solving of reactor model. A dynamic rate of polymerization and active site numbers $\mathrm{p}(0)$ over course of reaction was provided by the kinetic model, corresponding to development in reactor including changes caused by mixing phenomena and segregation.

Both model shared similarities in terms of the energy effects due to absorption and desorption of propylene have been neglected, the gas and solids velocities in the reactor are assumed to be constant. Main difference between the two model which explain the difference in the result of modeling is that in well mixed model, the polymerization reactor is considered to be a single phase (emulsion phase) where uniform temperature and composition exists throughout the bed. In Meier model, the reactor is divided in three sections which is the annulus, draft tube and cone section, with equilibrium assumed in each compartment and no heat transfer from the annulus to the draft tube section takes place.
The validated reactor model is used to predict the evolution of reactor behavior, which is the monomer concentration against time, under varying inlet reactor temperature, as shown in Fig. 2.

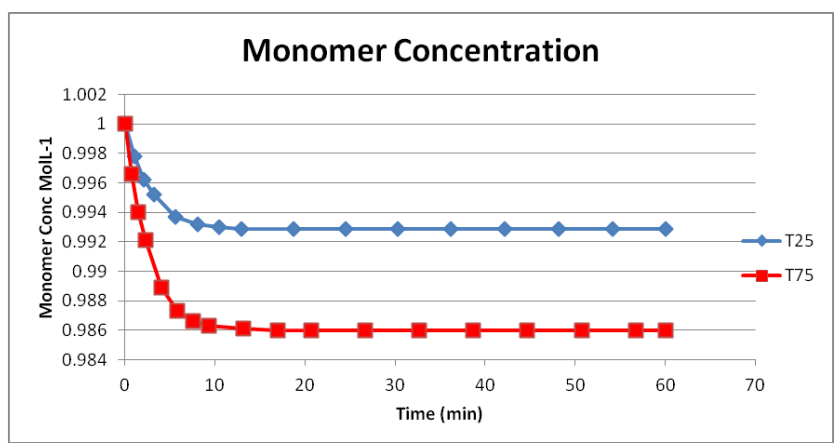

Fig. 2. Evolution of Reactor Behavior Monomer concentration against time predicted by model at temperature $25^{\circ} \mathrm{C}$ and $75^{\circ} \mathrm{C}$.

Figure 2 showed that at $25^{\circ} \mathrm{C}$ inlet temperature, the monomer concentration declined sharply from starting concentration to minimum concentration of $0.9929 \mathrm{~mol} / \mathrm{s}$ after $12.95 \mathrm{~min}$, whereas at $75^{\circ} \mathrm{C}$ inlet temperature, the monomer concentration reduce greatly from point of initiation to minimum concentration of $0.986 \mathrm{~mol} / \mathrm{s}$ after $16.93 \mathrm{~min}$.

The observation indicates higher monomer consumption at higher temperature, especially at the initiation of reaction. This is supported by steep increase of polymerization rate at higher temperature simulated in kinetic modeling. This observation can be explained as propagation rate constant $\mathrm{Kp}$, spontaneous deactivation and chain transfer to monomer is directly proportional to reactor temperature. Reduction of monomer concentration can also be cause by dip in solubility of propylene in solvent with increase in temperature at constant pressure.

\section{Conclusion}

A dynamic multi-scale model was developed for metallocene catalyzed polyolefin polymerization in fluidized bed reactor. Result of simulation matches with temperature profile of modelling result from literature and experiment data, with around $0.04 \%$ differences in maximum temperature reach during polymerization, even though previous studies that suggested simple well mixed model was not able to predict vertical temperature gradients because no segregation and no mixing phenomena have been taken into account. This problem was treated by incorporating kinetic behaviour into reactor modelling. Deviation of reactor temperature simulated by model is likely due to the assumption used where energy is transferred between the phases due to existence of temperature gradient between bubbles and emulsion as well as by the diffusing gas. Model predicted decrease in final monomer concentration from $0.9929 \mathrm{~mol} / \mathrm{s}$ to 0.986 $\mathrm{mol} / \mathrm{s}$, when initial reactor was raised from $25^{\circ} \mathrm{C}$ to $75^{\circ} \mathrm{C}$. This is due to higher monomer consumption at higher temperature, especially at the initiation of reaction. 


\section{References}

[1] Meier, G. B. Fluidized Bed Reactor for Catalytic Olefin Polymerization, 2000. ISBN 90-36514894. CIP -gegevens Koninklijke Bibliotheek, Den Haag.

[2] Uvarov, B.A., Tsevetkova, V.I., 1974. Development of a mathematical model for controlling the yield of propylene polymerization in loop reactors. Polim. Protsessy Appar., 165.

[3] Lepski, D.M., Inkov, A.M., 1977. Mathematical modelling of polymerization of propylene in loop reactors. Sb. Tr. Vses. Ob'edin. Neftekhlin 13, 34.

[4] Ferrero, M.A., Chiovetta, M.G., 1990. Preliminary design of a loop reactor for bulk propylene polymerization. Polym. Plast. Technol. Eng. 29 (3), 263.

[5] Reginato, A. S., Zacca, J. J., Secchi, A. R. (2003). Modeling and simulation of Propylene polymerization in nonideal loop reactors. American Institute of Chemical Engineers Journal, 49 (10), 2642-2654.

[6] Browning, B, Pitault. I;,Sheibat-Othman, N; Tioni, E; Monteil, V; McKenna, T.T.I; Dynamic modelling of a stopped flow fixed bed reactor for gas phase olefin polymerization, B. Browning et al. / Chemical Engineering Journal

[7] Sarkar, P., \& Gupta, S. K. (1992a). Steady state simulation of continuous-3ow stirred-tank slurry propylene polymerization reactors. Polymer Engineering and Science, 32, 732742.

[8] Sarkar, P., \& Gupta, S. K. (1992b). Simulation of propylene polymerization: An effcient algorithm. Polymer, 33, 1477-1485.

[9] Soares, J. B. P., \& Hamielec, A. E. (1996). Copolymerization of olefins in a series of continuous stirred-tank slurry-reactors using heterogeneous Ziegler-Natta and metallocene catalysts. I. General dynamic mathematical model. Polymers in Reaction Engineering, 4, 153-191.

[10] Debling, J. A., Han, G. C., Kuijpers, F., VerBurg, J., Zacca, J. J., \& Ray, W. H. (1994). Dynamic modeling of product grade transitions for ole9n polymerization processes. A.I.Ch.E. Journal, 40, 506- 520.

[11] Matos, V.; Mattos Neto, A. G.; Pinto, J. C. Method for Quantitative Evaluation of Kinetic Constants in Olefin Polymerizations. I. Kinetic Study of a Conventional Ziegler-Natta Catalyst Used for Propylene Polymerizations. J. Appl. Polym. Sci. 2001, 79, 2076.

[12] Neto, A. G. M., Freitas, M. F., Nele, M., Pinto, J. C. (2005). Modeling ethylene/1- Butane copolymerizations in industrial slurry reactors. Industrial \& Engineering Chemistry Research, 44, 2697-2715.
Touloupides,V; Kanellopoulos,V; Pladis, P; Kiparissides, C; Mignon,D, Van-Grambezen, $\mathrm{P}$; Modeling and simulation of an industrial slurry-phase catalytic olefin polymerization reactor series Chemical EngineeringScience65(2010)3208-3222.

[14] Ivanchev,S.S; Goncharenko, M. V; Kondratiev, N.Y; Saveliev, A.M; Sofiev, A.E; Mathematical modeling and experimental study of high-pressure ethylene polymerization reactors, Chemical Engineering Journal 134 (2007) 175-179.

[15] Prakash, Nikhil., Kinetic Modeling and Simulation of Metallocene Catalyzed Olefin Polymerization. 2013, Chemical Engineering Department (BITS-Pilani, Pilani campus).

[16] McAuley, K.B., MacGregor, J.F., Hamilec, A.E., 1990. A kinetic model for industrial gasphase ethylene copolymerization. AIChE J. 36, 837-850.

[17] Hatzantonis, H., Yiannoulakis, H., Yiagopoulos, A., Kiparissides, C., 2000. Recent developments in modeling gas-phase catalyzed olefin polymerization fluidized- bed reactors: the effect of bubble size variation on the reactor's performance Chem. Eng. Sci. 55, 3237-3259. 